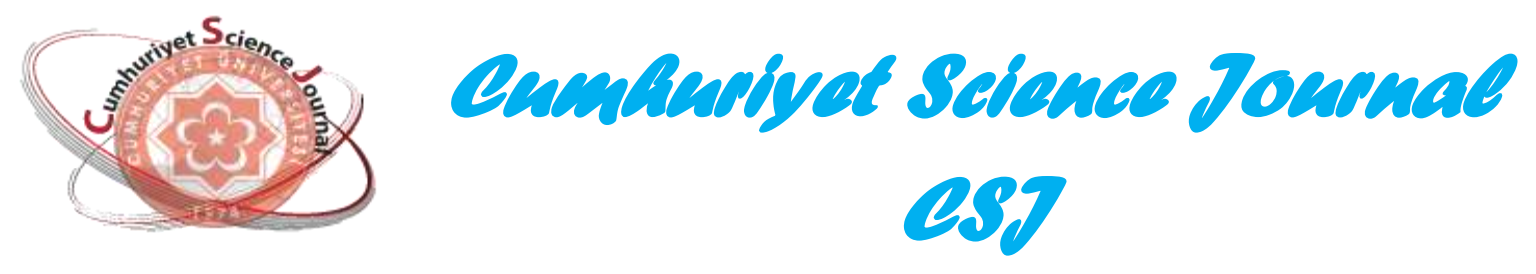

\title{
Investigation of Semiconductor Quantum Dots for Quantum Sensitized Solar Cells (QDSSCs)
}

\author{
Sabit HOROZ \\ Siirt University, Faculty of Arts and Science, Department of Physics, 56100, Siirt / TURKEY \\ Received: 05.06.2017; Accepted: 01.11.2017 \\ http://dx.doi.org/10.17776/csj.363334

\begin{abstract}
Semiconductor quantum dots (QDs) have recently attracted great interest as a material for solar energy conversion due to its versatile optical and electrical properties. QD-based solar cells (QDSSCs) are one of the evolving semiconductor QD solar cells that show promising developments for the new generation of solar cells. This work focuses on 1) quantum confinement effect in QDSSC, 2) multiple excitation production (MEG) of QDs, 3) production methods of QDs and 4) nanocrystalline photoelectrodes for solar cells. In addition, proposals are made for research on future QDSSCs. Although the QDSSC's effectiveness is still low, I believe there will be significant breakthroughs in the development of QDSSCs in the future.
\end{abstract}

Keywords: Multiple exciton generation (MEG) effect, quantum sensitized solar cells (QDSSCs), quantum dots (QDs), quantum confinement

\section{Kuantum Nokta Tabanlı Güneş Pilleri (QDSSCs) için Yariletken Kuantum Noktalarının İncelenmesi}

Özet: Yarı iletken kuantum noktaları (QD'ler) son zamanlarda çok yönlü optik ve elektriksel özelliklerinden dolayı güneş enerjisi dönüşümü için bir malzeme olarak büyük ilgi görmektedir. QD tabanlı güneş pilleri (QDSSCs), yeni nesil güneş pilleri için umut verici gelişmeler gösteren gelişen yariiletken QD güneş pillerinden biridir. Bu çalışmada, 1) QDSSC'lerde kuantum sınırlandırma etkisi, 2) QD'lerin çoklu eksitasyon üretimi (MEG), 3) QD'lerin üretim yöntemleri ve 4) güneş pilleri için nanokristalli fotoelektrodlar gibi konular üzerinde durulmuştur. Ayrıca, gelecekteki QDSSC'ler üzerine yapılacak araştırmalar için önerilerde bulunulmaktadır. QDSSC'lerin etkinliği halen düşük olmakla birlikte, ileride QDSSC'lerin geliştirilmesinde önemli atılımlar olacağı kanaatindeyim.

AnahtarKelimeler: Çoklu eksiton üretimi (MEG) etkisi, Kuantum nokta tabanlı güneş pilleri (QDSSCs), kuantum noktaları (QDs), kuantum sınırlandırma

\section{GíRiş}

Dünyanın dört yanındaki bilim insanları fosil yakıtların yerini alabilecek sürdürülebilir enerji kaynaklarından biri olan düşük maliyetli ve yüksek performanslı güneş pilleri üzerinde çalışmalar yapmaya başlamışlardır [1]. Geleneksel fotovoltaik cihazlardan biri olan p-n eklemli silikon kristalli güneş pilleri hem kurulum hem de üretim açısından yüksek maliyette oldukları için bilim dünyası ekonomik olarak düşük maliyetlerle yüksek verimler veren yeni nesi güneş pilleri üzerine yoğunlaşmıştır. Son zamanlarda yariiletken kuantum nokta tabanlı güneş pilleri (QDSSCs) maliyet açısından büyük ilgi görmüş ve yeni nesil güneş pilleri için umut verici gelişmeler göstermiştir $[2,4]$.

QDSSCs'ler, ilk kez 1991 yılından O'Regan ve Gratzel tarafindan yapilan deneyler sonucunda

\footnotetext{
* Corresponding author.Email address: sabithoroz@siirt.edu.tr

http://dergipark.gov.tr/csj C $\quad$ C2016 Faculty of Science, Cumhuriyet University
} 
ortaya çıkan boya tabanlı güneş pilleri (DSSCs)'nin türevi olarak görülebilir [5]. DSSCs'de yaygin olarak rutenyum polipiridin kompleksinin organik boyalanı duyarlaştırıcı olarak kullanılmaktadır. Görünür bölgesindeki 1ş1k hasatını arttırmak için yüksek performanslı duyarlaştırıcıların geliştirilmesine çaba gösterilmiştir [6,7]. Güneş 1şığ spektrumlarındaki bütün fotonları emmek için bir duyarlaştırıcı olarak ideal bir organik boyanın elde edilmesi her zaman zor olmuştur. $\mathrm{Bu}$ nedenle $\mathrm{CdS}$ [8], CdSe [9], PbS [10] ve InAs [11] gibi dar bant aralıklı yarilietken kuantum noktaları (QDs), mevcut olan organik boyalar yerine duyarlaştırıcı olarak kullanılmıştır [12,14]. Bu QD'lerin en temel özellikleri; 1-) boyuta bağlı olarak ayarlanabilir bant aralığı 2-) daha yüksek sönüm katsayısı 3-) su ve oksijene karşı daha yüksek kararlılık 4) bir foton emme ile çoklu eksiton üretimi (MEG) [15,17]. QD'lerin MEG etkisi açısından, teorik olarak QDSSCs'lerin fotovoltaik dönüşüm verimliliği \% 42'ye ulaşmıştır. Bu verimlilik, Schockley-Queisser sinırına göre yariiletkenler için elde edilmiş olan $\% 31$ oranından çok daha yüksektir [18].

Şekil 1 (a) geniş bant aralıklı bir mezo-gözenekli oksit film, QD'ler, bir elektrolit ve karş1 elektrottan oluşan bir QDSSC'nin hücre yapısını göstermektedir. Çalışma sırasında, fotonlar QD'ler tarafindan yakalanır ve bunlar nanokristalli oksit ve QD'ler arasındaki ara yüzeyde elektron-delik çiftleri oluşturur. Şekil 1 (b), $\mathrm{S}^{2-} / \mathrm{Sn}^{2-6}$ nin redoks çifti olarak kullanıldığ 1 bir QDSSC'de foto kaynaklı yük transfer süreçlerini göstermektedir [4]. Bu süreçler;

1. Uyarılmış bir QD'den $\mathrm{TiO}_{2}$ üzerine yük enjeksiyonu,

2. Elektronların elektrot yüzeyine taşınması,

3. Redoks çiftine delik aktarımı,

4. Redoks çiftinin yenilenmesi,

5. QD'den elektronların ve redoks çiftinin oksitlenmiş formunun rekombinasyonu

6. $\mathrm{TiO}_{2}{ }^{\prime}$ den elektronların ve oksitlenmiş redoks çiftinin ara yüzey rekombinasyonu
QD ve $\mathrm{TiO}_{2}$ arasındaki elektron transferinin, $10^{10}$ $10^{11} \mathrm{~s}^{-1}$ düzeyinde bir hız sabitine sahip olduğu ve bu değerlerin delik transferinden $\left(10^{7}-10^{9} \mathrm{~s}^{-1}\right)$ yüksek olduğu Kamat ve arkadaşları [19] tarafindan rapor edilmiştir. Bununla birlikte, mezo gözenekli $\mathrm{TiO}_{2}$ filmindeki elektron taşınımı, elektron ve delik transferlerinden daha yavaştır. $\mathrm{Bu}$ nedenle, rekombinasyon kayıları genel verimliliğin sınırlanmasında önemli bir rol oynamaktadır.
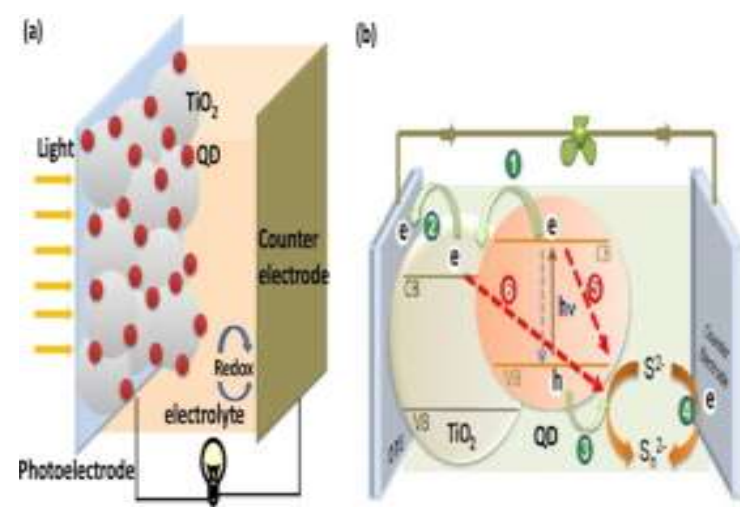

Şekil 1. (a) Bir kuantum nokta tabanlı güneş pilinin yapısının şematik gösterimi (b) Işı̆ğa dayalı yük transfer işlemlerinin şematik gösterimi [4].

\section{QDSSCs'ler için Kuantum Sınırlama Etkisi}

QD'ler, eksitonun Bohr yarıçapıyla karşılaştırılabilen boyutlara sahip olan son derece küçük yarı iletken nanokristallerdir [20]. Çoğu yarı iletken için, bir eksitonun Bohr yarıçapı 1-10 $\mathrm{nm}$ aralığındadır: örneğin, Si için $4.2 \mathrm{~nm}, \mathrm{CdS}$ için $3.1 \mathrm{~nm}$, CdSe için $6.1 \mathrm{~nm}$ ve $\mathrm{ZnO}$ için 2.2 nm'dir. Bununla birlikte, eksitonun Bohr yarıçapı bazı yarı iletkenler için çok büyük olabilmektedir. Örneğin; PbS için $20.4 \mathrm{~nm}$, PbSe için $46 \mathrm{~nm}$ ve $\mathrm{InSb}$ için $67.5 \mathrm{~nm}$ 'dir. Boyut etkisinden dolay1, QD'lerdeki elektronların davranışı, ilgili yı̆̆ın materyalindeki davranıştan farklıdır ve bu durum kuantum sinırlandırma etkisi olarak adlandırılır. Eksitonik Bohr yarıçapı büyük olan yarıiletken QD'lerde bu etki şiddetli bir şekilde görülür. Kuantum sinırlandırma etkisi nedeniyle, QD'nin bant boşluğu enerjisi, ( $\left.\mathrm{E}_{\mathrm{g}}\right)$ parçacık boyutunun azalmasıyla birlikte artar [21]. Eg'nin artmas1, QD tarafından emilmek için daha fazla enerjiye ihtiyaç duyulacağı anlamına gelmektedir. 
Böylece, QD'nin optik absorpsiyon dalga boyları aralığı, QD'nin boyutunu kontrol ederek ayarlanabilir. Ayarlanabilir Eg'ye sahip QD'lerin böyle bir özelliği, tam renkli görüntüler için ışık yayan diyotlarda (LED) ve istenen dalga boylarında optik absorpsiyon oluşturulması için QDSSCs'de kullanılmıştır [22, 23].

Lee ve arkadaşları [24] tarafindan kuantum sınırlandırma etkisi ile parçacık boyutu azaltılarak QD'lerin iletim band1 enerji $\left(\mathrm{E}_{\mathrm{cb}}\right)$ seviyesini yukarı çekilebileceğini ve bu durumun güneş enerjisi hücreleri için çok önemli olduğu vurgulanmıştır. Şekil 2a'da görüldüğü gibi, yığın

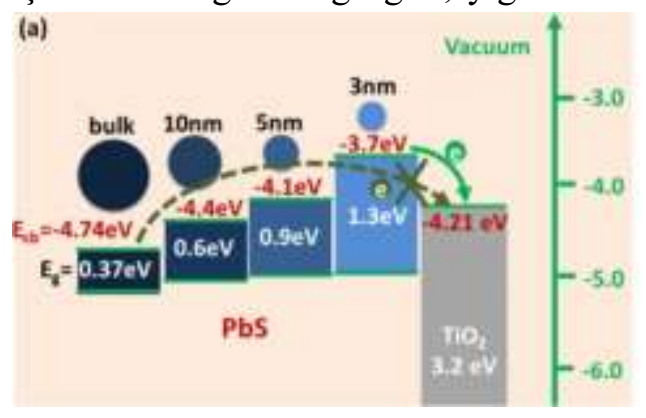

Şekil 2. (a) Parçacık boyutuna göre PbS'nin enerji seviyelerinin modülasyonunun şematik gösterimi. (b) PbS'ye ait $\mathrm{E}_{\mathrm{g}}$ ve partikül boyutu arasındaki ilişki $[21,25]$.

QDSSCs'ler için foto elektrotlu film üzerine adsorbe edilen daha fazla QD'ler elde etmek için daha küçük boyutlu QD'ler tercih edilir. Ayrıca, daha küçük boyutlu QD'ler daha büyük olanlara kıyasla daha yüksek bir elektron enjeksiyon hızına sahiptirler. Şekil 3, iletim bandları arasındaki enerji fark1 üzerindeki elektron transfer hızı sabitinin bağımlılığını ve iki farklı boyutlu CdSe
$\mathrm{PbS}$ yariiletkenin $\mathrm{E}_{\mathrm{cb}}$ 'si $-4.74 \mathrm{eV}$ olup $\mathrm{TiO}_{2}(-4.21$ eV)'ninkinden daha düşüktür. Böylelikle PbS'nin iletim bandındaki elektronun $\mathrm{TiO}_{2}$ 'in iletim bandına transferi zorlaşacaktır. Şekil 2b'de gösterildiği gibi, PbS'nin bant aralığı enerjisi, parçacık boyutu azaltılarak arttırılabilir. PbS'nin iletim band1 enerjisi $\mathrm{TiO}_{2}$ 'nin iletim band1 enerjisiyle eşleştiğinde, fotonlarla eksiton çiftlerinden bölünen elektronlar, $\mathrm{PbS}$ 'deki iletim bandından $\mathrm{TiO}_{2}$ 'nin iletim bandına kolayca aktarılabilir. Böylece kuantum sınırlandırma etkisi QDSSCs'lerin oluşturulması için gerekli bir koşul haline gelmektedir.

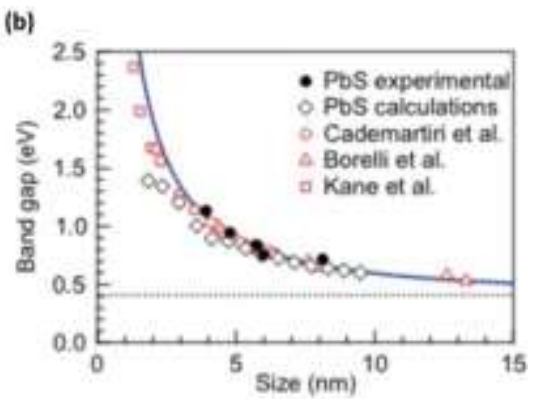

QD'den bir $\mathrm{TiO}_{2}$ nanopartikülüne elektron transferi prensibini göstermektedir [18]. CdSe$\mathrm{TiO}_{2}$ sisteminde, QD boyutunun azalması ile elektron transfer oranının arttığı görülmektedir. QD'ler için, bant aralığının arttırılmasının, bir foto elektrota elektron enjekte etmek için uygun iletim bant enerjilerine sahip olması beklenebilir. (a)

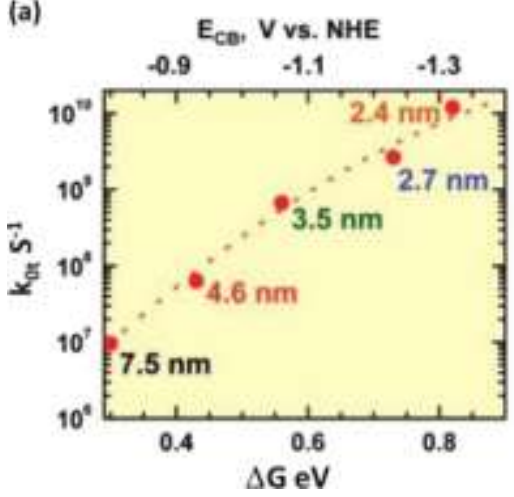

(b)

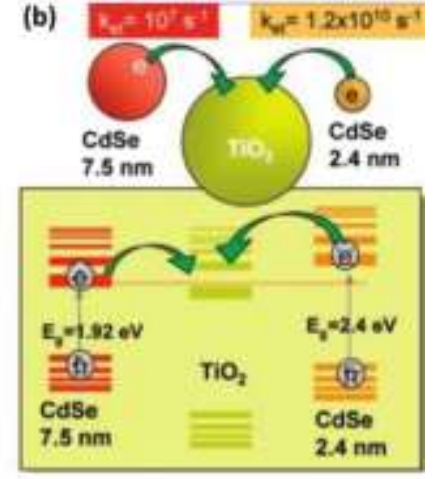

Şekil 3. (a) İletim bantları arasındaki enerji farkı üzerine elektron transfer hızı sabitinin bağımlılığı. (b) iki farklı boyutlu CdSe kuantum noktasından $\mathrm{TiO}_{2}$ nanopartikülüne elektron transferi prensibinin şematik gösterimi [18]. 
Bununla birlikte $E_{\mathrm{g}}^{\prime}$ nin artışı, sadece yüksek enerjili fotonların, QD tarafindan absorbe edilebileceğini ve Şekil 4'te gösterildiği gibi bu durumun QD'nin dalga boylarında kaymaya (kısa dalga boylarına doğru) yol açacağını göstermektedir. Çok küçük QD'ler, fotoelektrotlar için optik absorpsiyonun çok düşük olmasına yol açacağından dolayı bu durumun güneş pilleri üzerinde olumsuz etkileri vardır. $\mathrm{Bu}$ nedenle, QD'lerin bant enerji yapısını oksit film ile eşleştirmek ve geniş bir optik absorpsiyon dalga boyu elde etmek suretiyle en iyi güneş-elektrik dönüşüm verimliliği elde etmek mümkündür.

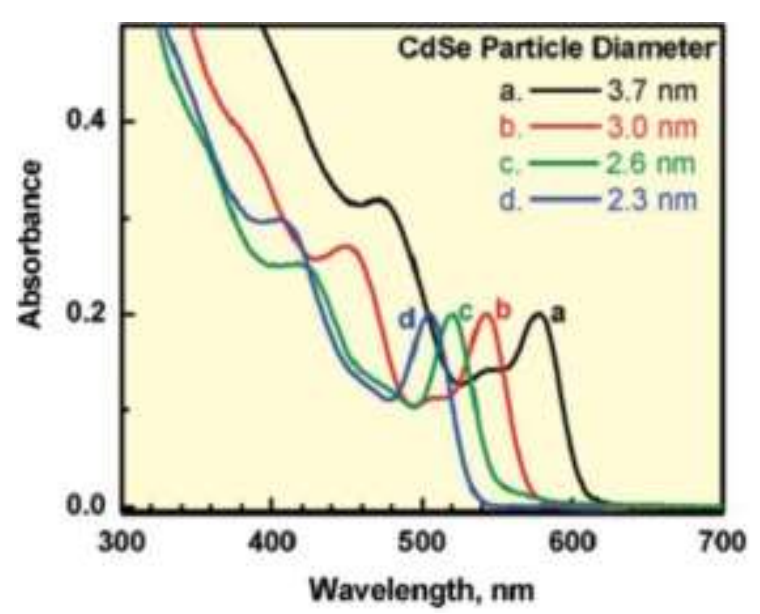

Şekil 4. 3.7, 3.0, 2.6 ve $2.3 \mathrm{~nm}$ çaplı CdSe kuantum noktalarına ait emilim spektrumları [26].
Tablo 1 QD'lerin ve oksitlerin genellikle QDSSC'ler üretmek üzere seçilen enerji bandı parametrelerini göstermektedir. Güneş pilleri oluşturmak için malzeme seçiminde esaslar şunlardır:

1) Optik absorpsiyon öncelikle aktif malzemeler band aralığı ile belirlenir ve bu nedenle dar ve doğrudan bant boşluklarına sahip malzemeler tercih edilir.

2) Aygıt yapısı, yüklerin güneş hücresi içinde son derece verimli bir şekilde taşınmasına izin verecek şekilde, uygun bir enerji gradyanını oluşturabilecek iyi eşleşen enerji düzeyleri seçerek tasarlanmalıdır [20].

Tablo 1. QDSSC'ler için en yaygın kullanılan materyallerin enerji bandı parametreleri [27-28].

\begin{tabular}{cccc}
\hline Yariiletken malzemeler & Bant aralı̆̆ $(\mathbf{e V})$ & İletim bandı (eV) & Valans bandı (eV) \\
\hline $\mathrm{CdS}$ & 2.4 & -3.98 & -6.38 \\
$\mathrm{CdSe}$ & 1.74 & -4.10 & -5.84 \\
$\mathrm{PbS}$ & 0.37 & -4.74 & -5.11 \\
$\mathrm{PbSe}$ & 0.27 & -4.93 & -5.20 \\
$\mathrm{ZnS}$ & 3.60 & -3.46 & -7.06 \\
$\mathrm{ZnSe}$ & 2.70 & -3.40 & -6.10 \\
$\mathrm{CuInS}_{2}$ & 1.50 & -4.06 & -5.56 \\
$\mathrm{TiO}_{2}$ & 3.20 & -4.21 & -7.41 \\
$\mathrm{ZnO}$ & 3.20 & -4.19 & -7.39 \\
$\mathrm{SnO}_{2}$ & 3.50 & -4.50 & -8.00 \\
\hline
\end{tabular}

\section{QDSSC'lerde MEG Etkisi}

QD'lerdeki MEG, absorbe edilen fotonlardaki aşırı enerjiyi kullanarak QDSSC'lerin güç dönüştürme verimliliğini arttırmanın başka bir yolu olarak düşünülmüştür. MEG etkisi, bir foton uyarımının sadece bir exciton üretebileceği klasik durumun aksine, bir foton uyarımı ile iki veya daha fazla 
elektron-delik çiftinin (eksitons) üretilmesidir. Teorik olarak, MEG etkisi, QD'lerin bant aralığının en az iki katı enerjili bir foton gerektirir. MEG etkisi göz önüne alındığında, bir QDSSC'nin teorik güç dönüştürme verimliliği \% 42 olarak tahmin edilmektedir ve bu değer geleneksel tek eklemli güneş pillerinin sahip olduğu değerden (\%31) yüksektir [29]. Semonin ve arkadaşlarının [30] yaptıkları deneysel çalışmada, $\mathrm{ZnO}$ ince film üzerine çökelmiş bir PbSe QD tabakasına dayanan bir p-n bağlantılı güneş pilinde, 400 nm'nin altındaki dalga boylarında $\% 100$ 'den daha yüksek bir dış kuantum verimliliğinin elde edilebileceğini göstermişlerdir. Böylece, çoklu eksitons üretmek için yüksek enerjili fotonların kullanılması bir QDSSC'nin operasyonel verimliliğini artırabilir [4].

MEG etkisi, bir yı̆̆ın (bulk) yarı iletken içinde de görülebilen bir olgudur. Bununla birlikte, fotonların enerjisi için gerekli eşik, QD'lerinkinden çok daha yüksektir. Yarı iletken $\mathrm{PbSe}$ için bulk malzemenin eşik enerjisi $1.75 \mathrm{eV}$ kadar yüksek iken, PbSe QD için bu değer $0.91 \mathrm{eV}$ 'dir. QD'lerde kolayca elde edilebilen MEG etkisinin olası sebepleri;

1) Elektron-delik $\left(\mathrm{e}^{-}-\mathrm{h}^{+}\right)$çiftleri korelasyona girer ve bu nedenle serbest taşıyıcılar yerine eksitonlar olarak var olurlar.

2) Ayrı elektron durumlarının oluşması nedeniyle sıcak elektron ve delik soğutma hızı yavaşlatılabilir.

3) Momentum iyi bir kuantum numaras1 değildir ve bu nedenle kristal momentumunu muhafaza etme ihtiyacı rahattır.

4) Auger süreçleri artan $\mathrm{e}^{-}-\mathrm{h}^{+}$Coulomb etkileşimi nedeniyle büyük oranda arttırılmıştır. Dolayısıyla, QD'lerde çok sayıda eksiton çiftinin üretimi, bulk yarı iletkenlerle karşılaştırıldığında artırılabilir [29].

MEG etkisi ile QD güneş pillerinin verimliliğinin arttırılması, kısmen büyük bir sorunla karş1 karşıya kalabilir. Çünkü MEG etkisinin uyartılmas1, nispeten yüksek enerjili fotonlara ve yüksek güç yoğunluğuna sahip bir pompa 1şığına gereksinim duyar. Güneş enerjisi teknolojileri üzerinde en büyük etkiyi yapmak için, MEG başlangıcının olabildiğince 2Eg'ye yakın olmasını sağlayarak MEG verimliliği daha da geliştirilmelidir [31].

\section{Güneş Pilleri için QD'lerin Üretim Yöntemleri}

QD duyarlaştırıcılar iki temelde farklı tekniklerle sentezlenebilir; Yerinde imalat ve önceden sentezlenmiş koloidal QD'lerin eklenmesi [32]. $\mathrm{Bu}$ teknikler büyük ölçekli üretimlerde de uygulanabilir. Fakat bunlar, QD’lerin parçacık büyüklüğü dağılımını hassas bir şekilde kontrolünü sağlayamazlar. Kimyasal Banyo Depolama (CBD) ve Ardışık İyonik Tabaka Adsorpsiyon ve Reaksiyonu (SILAR) yöntemleri QD hazırlı̆̆ için yaygın olarak kullanılır [33].

CBD, bir banyoda QD büyümesi gerçekleştiğinde, QD'leri ve nanopartikül filmleri biriktirmek için nispeten basit bir yöntemdir. Katyonik ve anyonik çözeltiler ayrı olarak hazırlanır ve yavaş reaksiyon için bir banyo çözeltisi oluşturmak üzere bir kap içine yerleştirilir. QD'ler, geniş bant aralıklı yarı iletken yüzeyine belirli bir süre banyo solüsyonuna daldırılarak büyütülür. Böylece, QD birikimi daldırma süresinin değiştirilmesiyle kontrol edilebilir. $\mathrm{Bu}$ yöntem, aynı zamanda, istikrarlı verim, sağlam yapışma ve iyi tekrarlanabilirlik gibi birçok avantaja sahiptir. Bununla birlikte, QD'lerin büyümesi; biriktirme süresi, çözelti bileşimi, sıcaklık ve mezo gözenekli film özellikleri gibi büyüme koşullarına bağlıdır [34].

SILAR yönteminde katyonik ve anyonik çözeltiler ayrı olarak iki behere yerleştirilir. $\mathrm{TiO}_{2}$ kaplı elektrot önce katyonik solüsyona batırılır ve daha sonra anodik çözelti içine daldırılır. Her bir daldırma adımı, durulama ve kurutma ile takip edilir. İki aşamalı daldırma prosedürü, tek bir SILAR döngüsü olarak kabul edilir. Büyütülen QD'lerin boyutu daldırma döngü sayısıyla kontrol edilebilir [35]. Senthamilselvi ve arkadaşları [36] yaptıkları çalışmada SILAR yönteminin, daha kısa bir işlem süresine ve stokiyometri oluşumuna bağlı olarak CBD'den daha iyi bir yaklaşım olduğunu bildirmiştir.

CBD ve SILAR yöntemlerinin yanı sıra QD'ler, çeşitli fonksiyonel gruplara sahip moleküler bağlayıcıları kullanarak da hazırlanabilir. Bu teknikte, QD'ler, merkaptopropiyonik asit, 
trioctilfosfin ve trioctilfosfin oksit gibi bağlayıcılar kullanılarak önceden sentezlenir. QD'ler, doğrudan yüzeyde absorpsiyon yoluyla bağlanma molekülleri kullanılmadan büyütülebilir, bu da yüksek düzeyde bir QD toplanmasına neden olabilir. $\mathrm{Bu}$ teknik aynı zamanda boyut ve dolayısıyla QD'lerin spektral emilim özelliklerinin hassas bir şekilde kontrol edilmesini sağlar [37, 38]. Bununla birlikte, bu teknikler, sadece QDSSC'lerin imalatında duyarlaştırıcı olarak QD'lerin performansını geliştirmektedir. QD'lerin enerji dönüşüm verimliliğini artırmak için optimizasyon çalışmaları yapılmalıdır.

\section{Güneş Pilleri için Nanokristal Foto Elektrotlar}

Geniş yüzey alanı nedeniyle, geleneksel $\mathrm{TiO}_{2}$ ve $\mathrm{ZnO}$ (geniş band aralıklı yarı iletkenler) gibi gözenekli nanokristalli filmler QD'lerin adsorpsiyonu için QDSSC'lerde kullanılmaktadır. $\% 5^{\prime}$ lik gibi yüksek güç dönüştürme verimliliğine sahip $\mathrm{TiO}_{2}$, yaygın olarak QDSSC'lerde foto elektrot olarak kullanılmaktadır. Örneğin, Hossain ve arkadaşları [39] yaptıkları deneyde, 1şık saçılım katmanlarını içeren CdSe'ye duyarlı $\mathrm{TiO}_{2}$ güneş pillerinin\% 5.21'lik bir güç dönüştürme verimliliğine sahip olduğunu rapor etmişlerdir. Kamat ve arkadaşları [2] $\mathrm{TiO}_{2}$ film üzerine büyütülen $\mathrm{Mn}$ katk1lı CdS-CdSe tabanlı QDSSC'lerin\% 5.4'lük bir güç dönüştürme verimliliği elde ettiğini bildirmiştir. Lee ve arkadaşları [40], benzeri görülmemiş derecede yüksek bir \% 5.6 güç dönüştürme verimliliğine sahip bir PbS-Hg QD duyarlı $\mathrm{TiO}_{2}$ güneş pili geliştirmişlerdir.

$\mathrm{ZnO}, \mathrm{TiO}_{2}$ 'ye iyi bir alternatif malzeme olarak kullanılmaktadır. çünkü enerji bandı yapısı ve fiziksel özellikleri $\mathrm{TiO}_{2}$ 'ye benzemektedir. Ancak, $\mathrm{TiO}_{2}$ 'ninkinden yaklaşık 4 kat daha fazla bir elektronik hareket kabiliyeti vardır [41, 42]. Buna ek olarak, benzersiz elektronik ve optik özellikler sunan $\mathrm{ZnO}$ kullanılarak anizotropik yapılar (nanoteller, nanorodlar ve nanotüpler gibi) oluşturmak kolaydır [43-44]. Dahası, bu nanoyapılarla oluşturulmuş bir fotoelektrolit film, QD'lerin dağılımı için yararlıdır [17]. QDSSC'ler için ZnO-nanoyapılı fotoelektrotlar son birkaç yıldır araştırılmaktadır [45, 47]. Bununla birlikte, muhtemelen $\mathrm{ZnO}$ 'da yüksek yüzey yük rekombinasyonundan dolay1, $\mathrm{ZnO}$ tabanlı QDSSC'lerin etkinliği, $\mathrm{TiO}_{2}$ tabanlı cihazların verimliliğinden daha düşüktür $[48,49]$. Yüksek yüzey yük rekombinasyonu, $\mathrm{ZnO}$ yüzeyinin birçok kusuruna bağlanabilir. Buna ek olarak, ZnO'nun kimyasal kararlılığ ${ }_{1}, \mathrm{TiO}_{2}$ 'den daha düşüktür [50].

\section{SONUÇLAR}

Son zamanlarda, yarı iletken QD'ler, yüksek absorpsiyon katsayıs1, kuantum sinırlamas1 (ayarlanabilir bant aralığ nedeniyle güneş enerjisi dönüşümü için ilgi gören malzemeler arasında yer almaktadır. QDSSC'ler, yeni nesil güneş pilleri için umut verici gelişmeler gösteren yarı iletken QD güneş pilleri üretmektedir. Gelecekteki çalışmalar güneş pillerinin performansını aşağıdaki gibi geliştirmeye odaklanmalıdır: 1) kuantum sınırlaması açısından optik absorpsiyon geniş bir dalga boyu aralığına sahip yeni yarı iletken QD'ler tasarlamak; 2) eşik enerjisini azaltarak QD'lerin MEG etkisini arttırmak; 3) daha fazla QD yüklemek ve yük rekombinasyonunu azaltmak için foto elektrot için uygun porozite oluşturmak. Yar1 iletken QD'lerin son gelişmeleriyle gelecekteki QDSSC'leri geliştirme konusunda büyük ilerlemeler beklenilmektedir.

\section{KAYNAKLAR}

[1]. Tada H., Fujishima M., Kobayashi H. Photodeposition of metal sulfide quantum dots on titanium(IV) dioxide and the applications to solar energy conversion. Chem. Soc. Rev. 2011; 40 (7): 4232-4243.

[2]. Santra P.K., Kamat P.V. Mn-Doped Quantum Dot Sensitized Solar Cells: A Strategy to Boost Efficiency over 5\%. J. Am. Chem. Soc.2002; 134(5): 2508-2511.

[3]. Ryu J., Lee S.H., Nam D.H., Park C.B. Rational design and engineering of quantum-dot-sensitized $\mathrm{TiO}_{2}$ nanotube arrays for artificial photosynthesis. Adv. Mater. 2011; 23(16): 1883-1888. 
[4]. Kamat P.V. Quantum Dot Solar Cells.- The Next Big Thing in Photovoltaics. J. Phys. Chem. Lett. 2013; 4 (6): 908-918.

[5]. Oregan B., Gratzel M. A low-cost, highefficiency solar cell based on dye-sensitized colloidal TiO2 films. Nature. 1991; 353: 737-740.

[6]. Bomben P.G., Robson K.C.D., Sedach P.A., Berlinguette C.P. On the Viability of Cyclometalated $\mathrm{Ru}(\mathrm{II})$ Complexes for Light-Harvesting Applications. Inorg. Chem.2009; 48 (20): 9631-9643.

[7]. Zhao H.C., Harney J.P., Huang Y.T., Yum J.H., Nazeeruddin M.K., Gratzel M., et al., Evaluation of a ruthenium oxyquinolate architecture for dye-sensitized solar cells. Inorg. Chem. 2012; 51(1): 1-3.

[8]. Panigrahi S, Basak D. J Colloid Interface Sci. 2011;364: 10-17.

[9]. Shen Q., Kobayashi J., Diguna L.J., Toyoda $\mathrm{T}$., Effect of $\mathrm{ZnS}$ coating on the photovoltaic properties of $\mathrm{CdSe}$ quantum dot-sensitized solar cells. J. Appl. Phys. 2008; 103: 084304.

[10]. Plass R., Pelet,S., Krueger J., Gratzel M., Bach U. Quantum Dot Sensitization of Organic-Inorganic Hybrid Solar Cells. J. Phys. Chem. B. 2002; 106 (31): 75787580.

[11]. Yu P., Zhu K., Norman A.G., Ferrere S., Frank A.J., Nozik A.J. Nanocrystalline $\mathrm{TiO}_{2}$ Solar Cells Sensitized with InAs Quantum Dots. J. Phys. Chem. B. 2006; 110 (50): 25451-25454.

[12]. Gonzalez-Pedro V., Xu X., Mora-Sero I., Bisquert J. Modeling high-efficiency quantum dot sensitized solar cells. Acs Nano.2010; 4(10): 5783-5790.

[13]. Yu X.Y., Liao J.Y., Qiu K.Q., Kuang D.B., Su C.Y. Dynamic study of highly efficient $\mathrm{CdS} / \mathrm{CdSe}$ quantum dot-sensitized solar cells fabricated by electrodeposition. Acs Nano. 2011; 5 (12): 9494-9500.

[14]. Cheng C.W., Karuturi S.K., Liu L.J., Liu J.P., Li H.X., Su L.T., et al., Quantum-DotSensitized $\mathrm{TiO}_{2}$ Inverse Opals for Photoelectrochemical Hydrogen Generation. Small. 2012; 8 (1): 37-42.
[15]. Zhu G., Pan L., Xu T., Sun Z.. CdS/CdSecosensitized $\mathrm{TiO}_{2}$ photoanode for quantumdot-sensitized solar cells by a microwaveassisted chemical bath deposition method. Acs Appl. Mater. Inter. 2011; 3(8): 31463151.

[16]. Lee Y.L., Lo Y.S.. Highly Efficient Quantum-Dot-Sensitized Solar Cell Based on Co-Sensitization of $\mathrm{CdS} / \mathrm{CdSe}$. Adv. Funct. Mater.2009; 19 (4): 604-609.

[17]. Tian J.J., Gao R., Zhang Q.F., Zhang S.G., Li Y.W., Lan J.L., et al.,. Enhanced Performance of CdS/CdSe Quantum Dot Cosensitized Solar Cells via Homogeneous Distribution of Quantum Dots in $\mathrm{TiO}_{2}$ Film. J. Phys. Chem. C. 2012; 116 (35): $18655-$ 18662.

[18]. Kamat P.V. Quantum Dot Solar Cells. Semiconductor Nanocrystals as Light Harvesters. J. Phys. Chem. C. 2008; 112 (48): 18737-18753.

[19]. Chakrapani V., Baker D., Kamat P.V., Understanding the Role of the Sulfide Redox Couple $\left(\mathrm{S}^{2-} / \mathrm{S}_{n}{ }^{2-}\right)$ in Quantum DotSensitized Solar Cells. J. Am. Chem. Soc. 2001; 133(24): 9607-9615.

[20]. Zhang Q., Uchaker E., Candelaria S.L., Cao G. Nanomaterials for energy conversion and storage. Chem. Soc. Rev. 2013; 42 (7): 3127-3171.

[21]. Segets D., Lucas J.M., Taylor R.N.K., Scheele M., Zheng H., Alivisatos A.P., et al., Determination of the quantum dot band gap dependence on particle size from optical absorbance and transmission electron microscopy measurements. Acs Nano. 2012; 6(10): 9021-9032.

[22]. Wood V., Bulović V. Colloidal quantum dot light-emitting devices. Nano Rev. 2010; 1: 5202.

[23]. Shibu E., Sonoda A., Tao Z., Feng Q., Furube A., Masuo S., et al. Energy materials: supramolecular nanoparticles for solar energy harvesting. Nano Rev.2013; 4: 2107.

[24]. Lee J.R.I., Meulenberg R.W., Hanif K.M., Mattoussi H., Klepeis J.E., Terminello L.J., et al., Experimental Observation of 
Quantum Confinement in the Conduction Band of CdSe Quantum Dots. Phys. Rev. Lett. 2007; 98: 146803.

[25]. Moreels I., Lambert K., Smeets D., De Muynck D., Nollet T., Martins J.C., et al., Size-dependent optical properties of colloidal $\mathrm{PbS}$ quantum dots. Acs Nano. 2009; 3, 3023-3030.

[26]. Kongkanand A., Tvrdy K., Takechi K., Kuno M., Kamat P.V. Quantum Dot Solar Cells. Tuning Photoresponse through Size and Shape Control of CdSe- $\mathrm{TiO}_{2}$ Architecture. J. Am. Chem Soc.2008; 130: 4007-4015.

[27]. Xu Y., Schoonen M.A.A. The absolute energy positions of conduction and valence bands of selected semiconducting minerals. Am. Mineral. 2000; 85: 543-556.

[28]. Kim .SH., Markovich G., Rezvani S., Choi S.H., Wang K.L., Heath J.R. Tunnel diodes fabricated from $\mathrm{CdSe}$ nanocrystal monolayers. Appl. Phys. Lett. 1999; 74: 317-319.

[29]. Nozik, A.J. Nanoscience and nanostructures for photovoltaics and solar fuels. Nano Lett. 2010; 10 (8): 2735-2741.

[30]. Semonin O.E., Luther J.M., Choi S., Chen H.Y., Gao J., Nozik A.J., et al. Peak external photocurrent quantum efficiency exceeding $100 \%$ via MEG in a quantum dot solar cell. Science 2011; 334 (6062): 15301533.

[31]. Beard M.C. Multiple Exciton Generation in Semiconductor Quantum Dots. J. Phys. Chem. Lett. 2011; 2 (11): 1282-1288.

[32]. Emin S., Singh S.P., Han L., Satoh N., Islam A. Colloidal quantum dot solar cells. Sol. Energy 2011; 85 (6): 1264-1282.

[33]. Halim M.A. Harnessing Sun's Energy with Quantum Dots Based Next Generation Solar Cell. Nanomaterials 2013; 3 (1): 2247.

[34]. Choi Y., Seol M., Kim W., Yong K., Chemical Bath Deposition of Stoichiometric CdSe Quantum Dots for Efficient Quantum-Dot-Sensitized Solar Cell Application. J. Phys. Chem. C 2014; 118 (11): 5664-5670.
[35]. Hu Y., Wang B., Zhang J., Wang T., Liu R., Zhang J., et al. Synthesis and photoelectrochemical response of $\mathrm{CdS}$ quantum dot-sensitized $\mathrm{TiO}_{2}$ nanorod array photoelectrodes. Nanoscale Res. Lett.2013; 8 (1): 222.

[36]. Senthamilselvi V., Saravanakumar K., Begum N.J., Anandhi R., Ravichandran A.T., Sakthivel B., et al. Photovoltaic properties of nanocrystalline $\mathrm{CdS}$ films deposited by SILAR and CBD techniques-a comparative study. J. Mater. Sci: Mater. Electron 2012; 23(1): 302-308.

[37]. Gimenez S., Mora-Sero I., Macor L., Guijarro N., Lana-Villarreal T., Go'mez R., et al. Improving the performance of colloidal quantum-dot-sensitized solar cells. Nanotechnol. 2009; 20: 295204.

[38]. Guijarro N., Lana-Villarreal T., Mora-Sero I., Bisquert J., Go'mez R. CdSe Quantum Dot-Sensitized TiO2 Electrodes: Effect of Quantum Dot Coverage and Mode of Attachmen. J. Phys. Chem. C 2009; 113 (10): 4208-4214.

[39]. Hossain M.A., James R.J., Shen C., Jia P.H., Koh Z.Y., Mathews N., et al., 2012. CdSe-sensitized mesoscopic $\mathrm{TiO}_{2}$ solar cells exhibiting $>5 \%$ efficiency: redundancy of CdS buffer layer. J. Mater. Chem. 2012; 22 (32): 16235-16242.

[40]. Lee J.W., Son D.Y., Ahn T.K., Shin H.W., Kim I.Y., Hwang S.J., et al. Quantum-DotSensitized Solar Cell with Unprecedentedly High Photocurrent. Sci. Rep. 2013; 3: 1050.

[41]. Zhang Q.F., Cao G.Z. Hierarchically structured photoelectrodes for dyesensitized solar cells. J. Mater. Chem.2011; 21 (19): 6769-6774.

[42]. Zhang Q.F., Chou T.R., Russo B., Jenekhe S.A., Cao G.Z. Aggregation of $\mathrm{ZnO}$ nanocrystallites for high conversion efficiency in dye-sensitized solar cells. Angew Chem. Int. Ed. Engl. 2008; 47(13): 2402-2406.

[43]. Zhang Q.F., Dandeneau C.S., Zhou X.Y., Cao G.Z. $\mathrm{ZnO}$ nanostructures for dye- 
sensitized solar cells. Adv. Mater. 2009; 21: 4087-108.

[44]. Zhang Q.F., Yodyingyong S., Xi J.T., Myers D., Cao G.Z. Oxide nanowires for solar cell applications. Nanoscale 2012; 4 (5): 1436-1445.

[45]. Seol M., Ramasamy E., Lee J., Yong K. Highly Efficient and Durable Quantum Dot Sensitized ZnO Nanowire Solar Cell Using Noble-Metal-Free Counter Electrode. J. Phys. Chem. C. 2011; 115: (44), 2201822024.

[46]. Yao C.Z., Wei B.H., Meng L.X., Li H., Gong Q.J, Sun H., et al. Controllable electrochemical synthesis and photovoltaic performance of $\mathrm{ZnO} / \mathrm{CdS}$ core-shell nanorod arrays on fluorine-doped tin oxide. J. Power Sources 2012; 207: 222-228.

[47]. Bora T., Kyaw H.H., Dutta J. Zinc oxidezinc stannate core-shell nanorod arrays for CdS quantum dot sensitized solar cells. Electrochim. Acta 2012; 68: 141-145.

[48]. Tian J.J., Zhang Q.F., Zhang L.L., Gao R., Shen L.F., Zhang S.G., et al. $\mathrm{ZnO} / \mathrm{TiO}_{2}$ nanocable structured photoelectrodes for $\mathrm{CdS} / \mathrm{CdSe}$ quantum dot co-sensitized solar cells. Nanoscale 2013; 5 (3): 936-943.

[49]. Tian J.J., Zhang Q.F., Zhang L.L., Gao R., Shen L.F., Zhang S.G., et al.. Energy materials: core/shell structural photoelectrodes assembled with quantum dots for solar cells. Nano Rev. 2013; 4: 21080.

[50]. Irannejad A., Janghorban K., Tan O.K., Huang H., Lim C.K., Tan P.Y., et al. Effect of the $\mathrm{TiO} 2$ shell thickness on the dyesensitized solar cells with $\mathrm{ZnO}-\mathrm{TiO} 2$ coreshell nanorod electrodes. Electrochim. Acta 2011; 58: 19-24. 